www.jmscr.igmpublication.org Impact Factor 5.244

Index Copernicus Value: 5.88

ISSN (e)-2347-176x ISSN (p) 2455-0450

crossref DOI: _http://dx.doi.org/10.18535/jmscr/v4i5.37

Journal Of Medical Science And Clinical Research

\title{
Immunohistochemical Analysis \& Correlation of EGFR and Ki-67 Expression Status with Clinicopathological Parameters in Head and Neck Squamous Cell Carcinomas: An Indian Perspective
}

\author{
Authors
}

\section{Dr Prerna Chadha ${ }^{1}$, Dr Nikhilesh Kumar ${ }^{2}$, Dr Rigvardhan ${ }^{3}$,} Dr Prashant Sengupta ${ }^{4}$, Dr Richa Ranjan

${ }^{1}$ Resident,Dept. Of Pathology, Command Hospital, Central Command, Lucknow

${ }^{2}$ Professor, Command Hospital, Central Command, Lucknow

${ }^{3}$ Associate Professor, Command Hospital, Central Command, Lucknow

${ }^{4}$ Associate Professor, Command Hospital, Central Command, Lucknow

${ }^{5}$ Assistant Professor, Command Hospital, Central Command, Lucknow

\section{INTRODUCTION}

Head and neck squamous cell carcinoma (HNSCC) is sixth most common neoplasm worldwide and despite the progress made in the diagnosis and treatment, the survivalof these patients has not improved significantly ${ }^{[1]}$. Therefore a vigilant search for newer diagnostic and prognostic markers along with fresh molecular targets is required for the prevention \& cure of HNSCCs and related tumors.

Epidermal growth factor receptor (EGFR) and $\mathrm{Ki}$ 67 labelling index are reflective of continued cell growth and multiplication, thereby inducing tumorigenesis $^{[2,3]}$. They are associated with disease progression, which in turn is a pointer towards tumor aggressiveness The importance of studying EGFR expression status lies in the fact that targeted therapy against this protein is available and has great potential ${ }^{[4]}$. However, extensive online search in indexed journals yielded very few results regarding the prognostic significance of Ki- 67 in HNSCC.
In this study, wecompared the immunohistochemical expression status of EGFR and KI-67 LI with various clinicopathological parameters.

\section{MATERIAL AND METHODS}

We studied 90 cases of HNSCCs, both prospectively and retrospectively which presented to us between Dec 2012 and May 2015. The cases were retrieved from the archives of Oncology centre of this tertiary care hospital. Hematoxylin and eosin ( $\mathrm{H} \& \mathrm{E})$ staining and immunohistochemistry (IHC) was performed for EGFR \& Ki67 on relevant sections as per the standard protocol. Negative and positive control slides were included in each IHC run (as recommended by the manufacturers). Relevant clinical data in the form of case sheets, laboratory \& radiological investigations were collected \& noted. Small biopsy specimens, cases with recurrent HNSCC post chemo/radiotherapy, cases other than squamous cell carcinoma, and cancers of the 
thyroid and salivary glands were excluded from this study.

\section{Immunohistochemistry staining procedure}

IHC was performed on $4 \mu \mathrm{m}$ formalin fixed sections obtained from paraffin blocks. The EGFR and Ki-67 Rabbit monoclonal antibody; ready to use kit (Thermo scientific) was used on sections fixed on Poly L Lysine coated slides. Endogenous peroxidase blocking was performed which was followed by the use of primary antibody (EGFR and $\mathrm{Ki}-67$ ) and then visualization reagent (labelled horse radish peroxidase secondary antibody). In the end, substrate chromogen solution (DAB) was used. Sections were then counterstained and mounted.

\section{Assessment of IHC results}

The assessment of IHC results was done on the basis of percentage of tumor cells showing membrane/cytoplasmic staining (for EGFR) and nuclear staining (for Ki-67). The staining intensity was assessed in the case of EGFR described by Seta sarkis et al ${ }^{[5]}$. For the purpose of our study, a score of $2+, 3+$ and $4+$ was taken as over expression while a score of $1+$ was taken as under expressed amongst the positive expression group. A score of 0 was taken as negative expression.

\section{Interpretation and scoring of $\mathrm{Ki} \quad 67$ immunohistochemical staining}

In this study, those cases were considered as immunopositive, which had more percentage positive than the mean value for this sample size. The staining pattern was nuclear and granular, while the mean value for our sample size was $55 \%$. The assessment was done as described by Brittany Barber et al ${ }^{[4]}$.

\section{Statistical analysis}

The statistical analysis was done using SPSS (Statistical Package for Social Sciences) Version 15.0 statistical Analysis Software. The values were represented in Number $(\%)$ and Mean \pm SD
(Standard deviation). Student ' $t$ ' test was used to test the significance of two means. Analysis of variance (ANOVA) test was used to compare the within group and between group variances amongst the study groups. The level of significance " $p$ " value was considered statistically significant if $<0.05$.

\section{RESULTS}

\section{Clinicopathological data}

The study sample comprised of 90 cases of HNSCCs which included 72 males $(80 \%)$ and 18 females (20\%). Most of the cases were well differentiated histopathologically $(\mathrm{n}=52 ; 57.8 \%)$ while 37 cases $(41.1 \%)$ were moderately differentiated. Only one case $(1.1 \%)$ was poorly differentiated. Maximum number of cases in this study presented with a clinical stage of $\mathrm{T} 2(\mathrm{n}=45$; $50.0 \%$ ) and most of the patients did not show nodal involvement at presentation $(n=67 ; 74.4 \%)$. In our study, the maximum depth of tumor ranged from $0.1 \mathrm{~cm}$ to $3.5 \mathrm{~cm} .48 .9 \%$ of the patients $(\mathrm{n}=44)$ had a tumor depth between $0.5-1 \mathrm{~cm}$. 


\section{JMSCR Vol||04||Issue||05||Page 10613-10619||May}

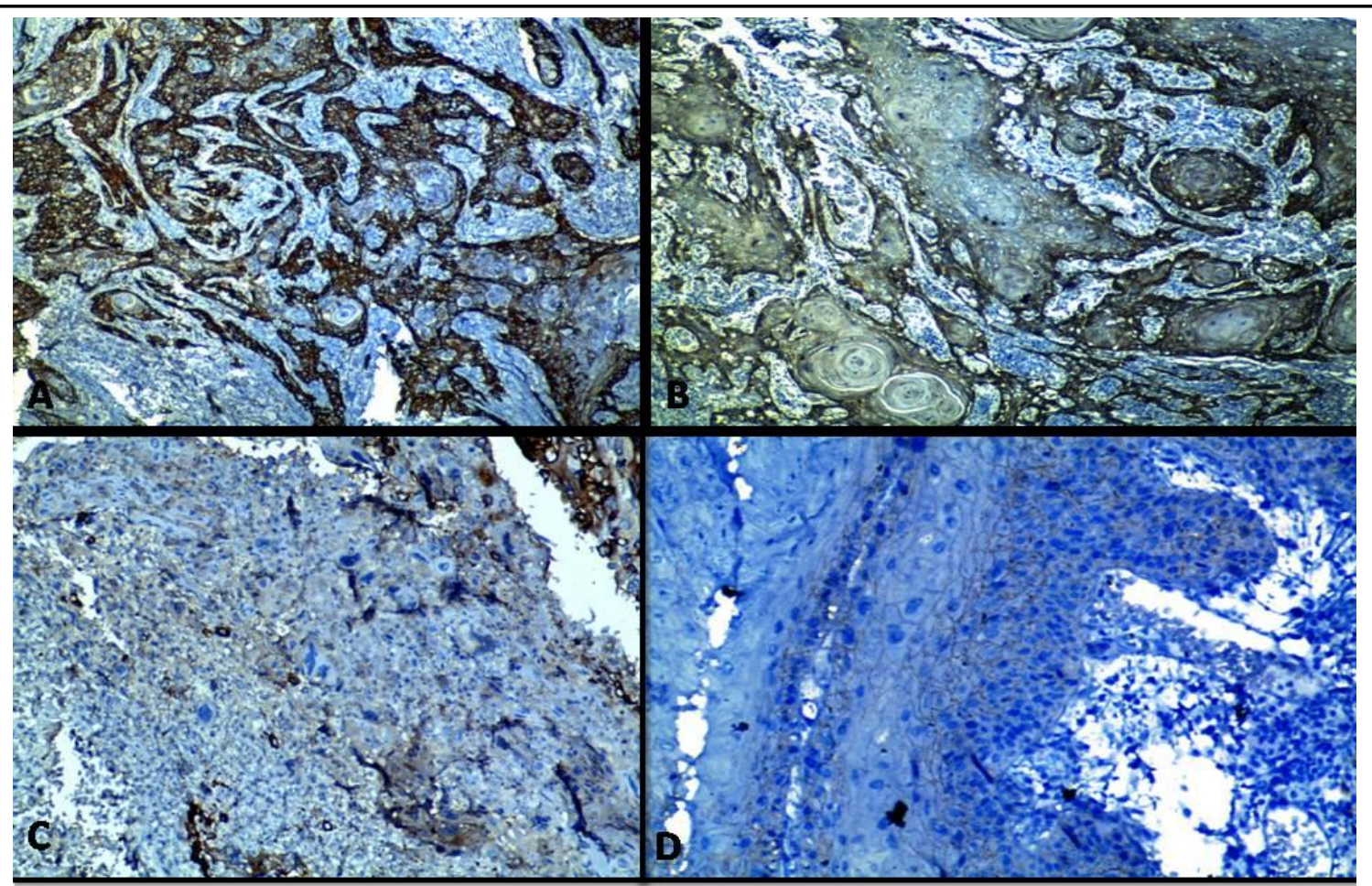

Fig 1

A : Immunopositivity for EGFR 4+ (20x) B : Immunopositivity for EGFR 3+ (20x) C : Immunopositivity for EGFR 2+(20x) D : Immunopositivity for EGFR 1+(20x)

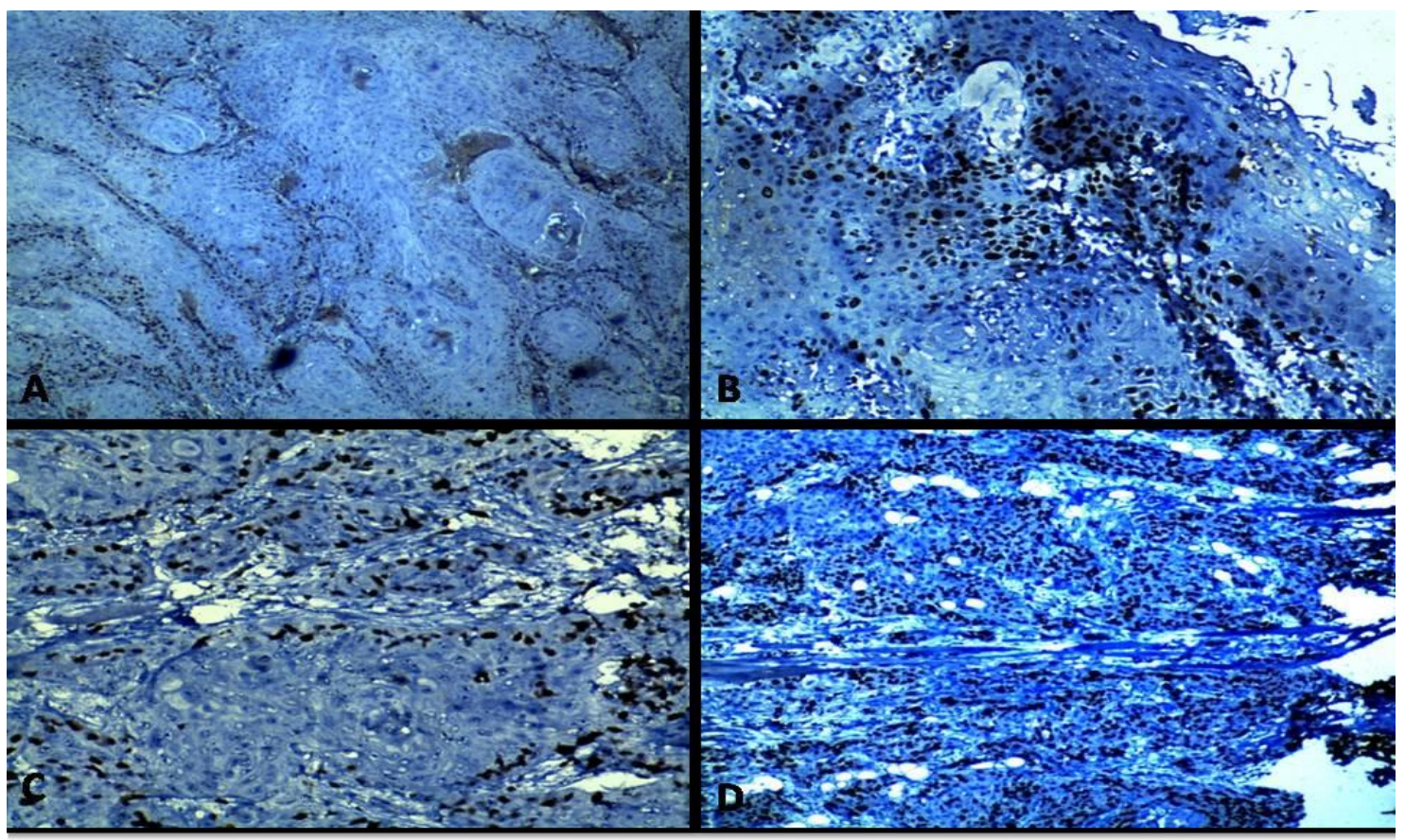

Fig 2

A : Ki 67 expression upto $25 \%$ (20x) B : Ki 67 expression 25 to 50\% (20x)

$\mathrm{C}$ : Ki 67 expression 50-75 \% (20x) D : Ki 67 expression > $75 \%$ (20x) 
Table 1: Association of EGFR expression with clinicopathological and TNM Staging parameters

\begin{tabular}{|c|c|c|c|c|c|}
\hline SN & Characteristic & $\begin{array}{l}\text { No. of } \\
\text { cases }\end{array}$ & Mean Expression & SD & $\begin{array}{l}\text { Statistical significance } \\
\text { "p" value }\end{array}$ \\
\hline \multirow[t]{4}{*}{1.} & Grade & & & & \\
\hline & Well differentiated & 52 & 3.25 & 0.76 & 0.017 \\
\hline & Moderately differentiated & 37 & 3.65 & 0.48 & \\
\hline & Poorly differentiated & 1 & 4.00 & 0.00 & \\
\hline \multirow[t]{5}{*}{2.} & Tumor size/Clinical Stage(T) & & & & \\
\hline & $\mathrm{T}_{1}$ & 21 & 3.05 & 0.97 & 0.030 \\
\hline & $\mathrm{T}_{2}$ & 45 & 3.49 & 0.51 & \\
\hline & $\mathrm{T}_{3}$ & 11 & 3.64 & 0.67 & \\
\hline & $\mathrm{T}_{4}$ & 13 & 3.62 & 0.51 & \\
\hline \multirow[t]{4}{*}{3.} & Nodal status(N) & & & & \\
\hline & $\mathrm{N}_{0}$ & 67 & 3.27 & 0.71 & \multirow[t]{3}{*}{0.094} \\
\hline & $\mathrm{N}_{1}$ & 15 & 3.93 & 0.26 & \\
\hline & $\mathrm{N}_{2}$ & 8 & 3.75 & 0.46 & \\
\hline \multirow[t]{3}{*}{4} & Distant metastasis(M) & & & & \multirow{3}{*}{0.231} \\
\hline & $\mathrm{M}_{0}$ & 88 & 3.41 & 0.69 & \\
\hline & $\mathrm{M}_{1}$ & 2 & 4.00 & 0.00 & \\
\hline \multirow[t]{6}{*}{5 . } & Tumor Depth (maximum) & & & & \\
\hline & $<=0.5 \mathrm{~cm}$ & 7 & 3.43 & 0.54 & \multirow[t]{5}{*}{0.361} \\
\hline & $0.5-1 \mathrm{~cm}$ & 44 & 3.41 & 0.50 & \\
\hline & $1-1.5 \mathrm{~cm}$ & 17 & 3.18 & 1.19 & \\
\hline & $1.5-2 \mathrm{~cm}$ & 12 & 3.67 & 0.49 & \\
\hline & $>2 \mathrm{~cm}$ & 10 & 3.60 & 0.52 & \\
\hline \multirow[t]{4}{*}{6.} & lymphovascular/ perineural invasion & & & & \\
\hline & None & 71 & 3.30 & 0.71 & \multirow[t]{3}{*}{0.002} \\
\hline & Lymphovascular invasion present & 17 & 3.88 & 0.33 & \\
\hline & Lymphovascular +Perineural & 2 & 4.00 & 0.00 & \\
\hline
\end{tabular}

Table 2: Association of Ki-67 expression with clinicopathological and TNM Staging parameters

\begin{tabular}{|c|c|c|c|c|c|}
\hline SN & Characteristic & $\begin{array}{ll}\begin{array}{l}\text { No. } \\
\text { cases }\end{array} & \text { of } \\
\end{array}$ & $\begin{array}{l}\text { Mean } \\
\text { Expression }\end{array}$ & SD & $\begin{array}{l}\text { Statistical significance } \\
\text { "p" value }\end{array}$ \\
\hline \multirow[t]{4}{*}{1.} & Grade & & & & \\
\hline & Well differentiated & 52 & 50.38 & 16.56 & 0.002 \\
\hline & Moderately differentiated & 37 & 62.22 & 14.51 & \\
\hline & Poorly differentiated & 1 & 75.00 & 0.00 & \\
\hline \multirow[t]{5}{*}{2.} & Tumor size/Clinical Stage(T) & & & & \\
\hline & $\mathrm{T}_{1}$ & 21 & 49.29 & 22.10 & \multirow[t]{4}{*}{0.011} \\
\hline & $\mathrm{T}_{2}$ & 46 & 55.56 & 13.37 & \\
\hline & $\mathrm{T}_{3}$ & 11 & 52.27 & 18.22 & \\
\hline & $\mathrm{T}_{4}$ & 13 & 68.23 & 9.17 & \\
\hline \multirow[t]{4}{*}{3.} & Nodal status(N) & & & & \\
\hline & $\mathrm{N}_{0}$ & 67 & 51.07 & 15.66 & \multirow{3}{*}{$<0.001$} \\
\hline & $\mathrm{N}_{1}$ & 15 & 73.33 & 7.24 & \\
\hline & $\mathrm{N}_{2}$ & 8 & 59.38 & 16.36 & \\
\hline \multirow[t]{3}{*}{4.} & Distant metastasis(M) & & & & \\
\hline & $\mathrm{M}_{0}$ & 88 & 55.53 & 16.95 & \multirow[t]{2}{*}{0.965} \\
\hline & $\mathrm{M}_{1}$ & 2 & 55.00 & 0.00 & \\
\hline \multirow[t]{6}{*}{5.} & Maximum tumor depth & & & & \\
\hline & $<=0.5 \mathrm{~cm}$ & 7 & 45.71 & 25.1 & \multirow[t]{5}{*}{0.270} \\
\hline & $0.5-1 \mathrm{~cm}$ & 44 & 56.48 & 14.8 & \\
\hline & $1-1.5 \mathrm{~cm}$ & 17 & 54.24 & 20.4 & \\
\hline & $1.5-2 \mathrm{~cm}$ & 12 & 52.92 & 9.9 & \\
\hline & $>2 \mathrm{~cm}$ & 10 & 63.50 & 17.0 & \\
\hline \multirow[t]{4}{*}{6.} & Lvi/Pni & & & & \\
\hline & None & 71 & 51.34 & 10.04 & \multirow{3}{*}{$<0.001$} \\
\hline & Lymphovascular & 17 & 70.29 & 7.80 & \\
\hline & Lympho+Perineural & 2 & 78.50 & 2.12 & \\
\hline
\end{tabular}




\section{Evaluation of IHC results}

EGFR expression score was found to be $4+$ in 45 $(50.0 \%)$ (fig 1A) cases, $3+$ in $41(45.6 \%)$ (fig1B) cases, $2+$ in 1 (1.1\%) (fig1C) and $1+$ in $3(3.3 \%)$ (fig1D) cases respectively. For the purpose of our present study, score of $2+, 3+$ and $4+$ were taken as indicators of over expression. Hence, $96.7 \%$ of the cases showed EGFR over expression

Ki-67 expression was seen to be upto $25 \%$ in 7 (7.8\%) (fig2A) cases, between 25 and $50 \%$ in 27 (30\%) (fig2B) cases, $50-75 \%$ in $47(52.2 \%)$ (fig2C) and $>75 \%$ in 9 (10\%) (fig2D) cases. In case of Ki-67 labelling index (LI), values $>55 \%$ (mean value) were taken as a high mitotic index. The Ki-67 LI was high in $47.7 \%$ of the cases.

\section{Association between EGFR expression and clinicopathological parameters}

EGFR expression showed a significant association with the histopathological grade of the tumor, tumor size and presence of lymphovascular/ perineural invasion (lvi/pni) $(\mathrm{p}<0.05)$. No significant association was found with maximum tumor depth, nodal status or distant metastasis at presentation. The results are summarised in table 1.

\section{Association between Ki-67 expression and clinicopathological parameters}

A high Ki-67 LI was seen in higher grade tumors and higher clinical stages. Highly significant correlation $(\mathrm{p}<0.01)$ was found between Ki-67 LI and nodal metastasis and lymphovascular/ perineural (lvi/pni) invasion while no significant association could be seen with maximum tumor depth or distant metastasis. Results are summarised in table 2.

\section{DISCUSSION}

EGFR is a member of the erbB family, which on binding to its natural ligands, results in the auto activation of tyrosine kinase. This process activates multiple intracellular signalling pathways, which impacts tumor metastasis and tumor angiogenesis ${ }^{[5]}$. Despite extensive study, the role of EGFR in the prognosis of HNSCCs remains questionable ${ }^{[4,6,7]}$.

Ki-67 has proved to be an excellent marker for determining the growth fraction of a given cell population. The Ki-67 LI is often associated with disease progression, and has therefore been used as an indicator of tumor aggressiveness in various malignancies ${ }^{[4]}$. Studies pertaining to the expression of Ki-67 LI in HNSCCs with respect to various clinicopathologic variables are scarce ${ }^{[4,8]}$. In our study, $51.1 \%$ of the patients were aged above 60 years with mean age being $61.33 \pm 10.38$ years. The majority of the patients were males $(\mathrm{n}=72 / 90 ; 80 \%)$ and there were $18(20 \%)$ females. The ratio of males to females was $4: 1$.

The staining pattern for EGFR was cytoplasmic with a membranous accentuation while it was nuclear (granular) for Ki-67. The staining intensity and extent was stronger in the peripheries of tumor islands in case of EGFR. This is because the staining reaction varies with cellular differentiation and therefore reiterates the presence of these receptors in undifferentiated cells ${ }^{[5]}$.

For Ki-67 too, the staining was predominantly limited to the peripheries of tumor nests. This is in keeping with the high proliferative activity of the basal type cells located in this region, as observed by other researchers as well ${ }^{[8]}$. Both EGFR and Ki-67 immunopositivity was seen in all of the cases in our study, however, EGFR over expression was found in $96.7 \%$ of the cases $(\mathrm{n}=87)$, while a high $\mathrm{Ki}-67 \mathrm{LI}(>55 \%)$ was seen in $47.7 \%$ of the cases $(n=43)$.

In this study, the mean expression of EGFR and the Ki-67 LI were significantly lower among the well differentiated histological types as compared to poorly differentiated and moderately differentiated types $(\mathrm{p}=0.017 ; 0.002)$. An inverse relationship between differentiation and EGFR \& $\mathrm{Ki}-67$ expression is suggested, and on the assumption that more undifferentiated tumors are more aggressive, both EGFR expression and Ki67 LI correlate well with tumor aggressiveness. ${ }^{[5,9]}$. 
Significant correlation was found between EGFR immunopositivity and high Ki-67 LI with the tumor size. However, no significant association was found with the expression of either of these receptors with the tumor depth. However, few studies in indexed literature derived a significant correlation between the tumor proliferative index and maximum tumor depth ${ }^{[4,5]}$.As more work is required in this area, these results must therefore be interpreted with caution.

Statistically, no significant correlation could be found between EGFR expression status and nodal metastasis in our study. However, this subject has been a matter of controversy as studies with opposing results have also been published in indexed literature ${ }^{[3,4,10]}$. This is in stark contrast to the highly significant correlation $(\mathrm{p}<0.001)$ found between a high KI-67 proliferation rate and nodal metastatic disease at presentation. Although a set cut-off could not be found in this study, it is prudent to note that the $\mathrm{Ki}-67 \mathrm{LI}$ might prove to be an extremely good marker in predicting occult metastases.

In our study, $78.9 \%$ of the patients $(n=71)$ did not show lvi/pni. 17 (18.9\%) showed only lvi, while 2 (2.2\%) showed both lvi and pni. Pni alone was not seen. We found a significant association between lvi/pni and EGFR over expression $(\mathrm{p}=0.002)$. This finding reiterates the prognostic implication of EGFR in HNSCCs as, lvi/pni have been regarded as good independent prognostic markers in this disease. There's a paucity of literature studying the correlation between EGFR and lvi/pni ${ }^{[11,12]}$.Our study attempts to shed some light upon this unexplored area. These results might indicate that, the role of EGFR in tumor metastasis is via lympho vascular spread. Another possibility exists that tumors having over expression of EGFR, which were also found to be of a higher grade, had an earlier involvement of vessels or nerves.

Our study highlighted a significant increase in the mean Ki-67 expression with tumors showing lvi/pni ( $\mathrm{p}<0.001)$. To the best of our knowledge, no study has been published previously in indexed literature pertaining to the association between lvi/pni and Ki-67 LI. These results reiterate the prognostic implication of Ki-67 LI.

No significant association was found between EGFR over expression or a high Ki-67 LI with distant metastasis.

\section{CONCLUSION}

EGFR expression is related to tumor growth, differentiation and aggressiveness and is therefore a strong independent prognostic indicator in HNSCCs. A high Ki-67 LI is associated with a higher proliferation rate and aside from acting as a reliable prognostic marker for tumour aggressiveness, it may aid in the identification of patients with clinically negative lymph nodes that are at a considerable risk for occult metastases.

This is a pilot study showing promising results with encouraging leads and although both these markers have been studied separately, their comprehensive analysis together has not been attempted previously in HNSCCs. Both EGFR \& $\mathrm{Ki}-67$ may serve as reliable biologic markers to identify high-risk subgroups and to guide therapy.

\section{FINANCIAL SUPPORT AND SPONSORSHIP Nil}

CONFLICT OF INTEREST All authors have none to declare.

\section{REFERENCES}

1. More Y, D'Cruz AK. Oral Cancer: Review of current management strategies. Natl Med J India. 2013 May-Jun; 26(3):152-8

2. Zimmermann M, Zouhair A, Azria D, Ozsahin M. The epidermal growth factor (EGFR) in head and neck cancer: its role and treatment implications. RadiatOncol. 2006;1:11-15.

3. Scholzen T, Gerdes J. The Ki-67 protein: from the known and the unknown.J Cell Physiol. Mar 2000; 182(3):311-22.

4. Barber BR, Biron VL, Klimowicz AC, Puttagunta L, Côté. Molecular predictors of locoregional and distant metastases in 
oropharyngeal squamous cell carcinoma. Journal of Otolaryngology- Head and Neck Surgery.2013;42:53.

5. Sarkis SA, Abdullah BH, Majeed BA, Nazar G. Biochemical markers EGFR , VEGF, PCNA, P53 and D2-40 in head and neck squamous cell cancers. Head Neck Oncol. 2010; 2: 13.

6. Kalyankrishna S, Grandis JR. Epidermal growth factor receptor biology in head and neck cancer. J ClinOncol. 2006 Jun 10; 24 (17):2666-72.

7. Smith BD, Smith GL, Carter D. Molecular marker expression in oral and oropharyngeal squamous cell carcinoma. Arch Otolaryngol Head Neck Surg. 2001;127:780-785.

8. Smita SB, Radhika MB, Paremala K, Sudhakara M.Expression of Ki-67 in normal oral epithelium, leukoplakic oral epithelium and oral squamous cell carcinoma. J Oral MaxillofacPathol. 2014 May-Aug; 18(2): 169-176

9. Ashraf MJ, Maghbul M, Azarpira N and Khademi B. Expression of Ki-67 and P53 in primary squamous cell carcinoma of the larynx. Indian J PatholMicrobiol. 2010;53 (4):661-5.

10. Gröbe A, Eichhorn W, Fraederich M, Kluwe L, Vashist YJ. Immunohistochemical and FISH analysis of EGFRand its prognostic value in patients with oral squamous cell carcinoma. Oral Pathol Med.2014 Mar;43(3):205-10.

11. Lin YT, Chien CY, Lu CT, Lou SD, Lu H, Huang CC. Triple-positive pathologic findings in oral cavity cancer are related to a dismal prognosis. Laryngoscope. 2015 Sep;125(9):E300-5. doi: 10.1002/lary.25463. Epub 2015 Jul 7.

12. Yeh CF, Li WY, Yang MH, Chu PY. Neck observation is appropriate in T1-2, cN0 oral squamous cell carcinoma without perineural

invasion

or

lympho vascularinvasion. Oral Oncol.2014Sep; 50

(9):85762. 